\title{
DESENVOLVIMENTO E VALIDAÇÃO DE MÉTODO ANALÍTICO PARA DOSEAMENTO DA SUSPENSÃO ORAL DE DIDANOSINA RECONSTITUIDO COM MYLANTA PLUS ${ }^{\circledR}$
}

\author{
L. F. BEZERRA da SILVA ${ }^{1}$, S. GRANGEIRO Jr², B. A. dos SANTOS ${ }^{2}$, C. R. N. SILVA \\ CABRAL $^{2}$, T. Q. ROCHA da COSTA ${ }^{2}$ A. K. M. SANTANA ${ }^{2}$. \\ ${ }^{1}$ Centro Universitário Tabosa de Almeida - UNITA- ASCES \\ ${ }^{2}$ Laboratório Farmacêutico do Estado de Pernambuco-LAFEPE \\ E-mail para contato: aila.santana@lafepe.pe.gov.br
}

RESUMO - Didanosina (DDI) oral é usada para tratamento da infecção pelo vírus da imunodeficiência humana (HIV 1) em adultos e crianças, $O$ antiácido Mylanta plus ${ }^{\circledR}$ é utilizado para evitar a degradação ácida do didanosina. A validação é um aspecto fundamental para garantir que os resultados forneçam informações confiáveis. Este trabalho teve como objetivo desenvolver e validar o método analítico de doseamento da didanosina suspensão oral reconstituída com Mylanta plus ${ }^{\circledR}$ por cromatografia líquida de alta eficiência (CLAE). Foi utilizada nas condições cromatográficas a fase estacionária: coluna luna C-18250 $\times 4.6$ mm $100 \mathrm{~A}^{\circ}$; fase móvel em gradiente, utilizando soluções de tampão de acetato de sódio pH 6.5, metanol e água, como diluente; fluxo de $1 \mathrm{~mL} / \mathrm{min}$; volume de injeção de $20 \mu \mathrm{L}$; tempo de corrida de 20 minutos; a temperatura do forno a $25^{\circ} \mathrm{C}$; e o detector a 254nm. O padrão e as amostras na concentração $100 \mu \mathrm{g} / \mathrm{mL}$. A linearidade foi significativa, com um coeficiente de correlação de 0,9999. $O$ método apresentou-se seletivo, pois não observou nenhum interferente no mesmo tempo de retenção da didanosina. O método apresentou-se preciso, exato e robusto. Assim, concluímos que o método pode ser utilizado na rotina laboratorial do LAFEPE, pois o mesmo atendeu as exigências analiticas conforme preconizado pela resolução aplicada.

Palavras chave: Cromatografia líquida de alta eficiência, quantificação de fármaco, LAFEPE.

ABSTRACT - Oral Didanosine (DID) is used to treat human immunodeficiency virus (HIV 1) infection in adults and children. The antacid Mylanta plus ${ }^{\circledR}$ is used to prevent acid degradation of DID. Validation is a critical aspect of ensuring that the results provide reliable information. This study aimed to develop and validate the analytical method of DID reconstituted with Mylanta plus ${ }^{\circledR}$ by high performance liquid chromatography (HPLC). The stationary phase was used in the chromatographic conditions: Luna column C-18 $250 \times 4.6 \mathrm{~mm} 100 \mathrm{~A}^{\circ}$; gradient mobile phase, using pH 6.5 sodium acetate buffer solutions, methanol 
and water as the diluent; flow rate of $1 \mathrm{~mL} / \mathrm{min}$; injection volume of $20 \mu \mathrm{L} ; 20$ minute running time; the oven temperature at $25^{\circ} \mathrm{C}$; and the detector at $254 \mathrm{~nm}$. The standard and the sample solutions were at $100 \mu \mathrm{g} / \mathrm{mL}$. Linearity was significant, with a correlation coefficient of 0.9999. The method was selective, as it did not observe any interferences in the same retention time of didanosine. Still, it was precise, accurate and robust. Thus, we conclude that the method can be used in the laboratory routine of the LAFEPE, since it met the analytical requirements as recommended by the resolution applied.

Key words: High-performance liquid chromatography, Quantitation of drug, LAFEPE.

\section{INTRODUÇÃO}

As normas de Boas Práticas de Fabricação (BPF) vigentes exigem que os métodos analíticos sejam validados a fim de assegurar a conformidade dos produtos farmacêuticos em relação às especificações estabelecidas, devem atender aos padrões de qualidade conforme exigências dos órgãos reguladores (BRASIL, 2010).

O planejamento dos estudos de validação é um aspecto fundamental para garantir que os resultados obtidos reflitam a operação dos procedimentos analíticos e que o método forneça informações confiáveis (BRASIL, 2010).

Didanosina (DDI) oral é usada para tratamento da infecção pelo vírus da imunodeficiência humana (HIV 1) em adultos e crianças, em combinação com outros agentes antirretrovirais. Didanosina não deve ser usada isoladamente no tratamento da infecção pelo HIV (BRASIL,2006). O antiácido Mylanta plus ${ }^{\circledR}$ é utilizado para evitar a degradação ácida do didanosina (André Filho, N, 2009).

Este trabalho tem como objetivo desenvolver e validar o método analítico de doseamento da Didanosina Solução Oral reconstituída com o Mylanta plus ${ }^{\circledR}$ por cromatografia líquida de alta eficiência (CLAE), seguindo a resolução vigente.

\section{MATERIAIS E MÉTODOS}

Foi utilizado o padrão primário USP Didanosina (Lote F0G088), o padrão secundário de Didanosina (Lote 17577), LAFEPE Didanosina pó para suspensão oral lote 16060001, Mylanta plus ${ }^{\circledR}$ lote 331131 (Johnson \& Johnson ${ }^{\circledR}$ ).

Condições cromatográficas: Coluna Luna C-18 250x4.6 mm 100A ${ }^{\circ}$, fase móvel gradiente soluções de tampão de acetato de sódio pH 6.5 (solução A) e metanol (solução B), diluente a

água ultrapura, fluxo de $1 \mathrm{~mL} / \mathrm{min}$, temperatura do forno de $25^{\circ} \mathrm{C}$, detector UV$254 \mathrm{~nm}$, volume $20 \mu \mathrm{L}$, e o tempo de corrida de 20 minutos. Gradiente: Tempo(min) 0-2: A-80\% e B-20\%; Tempo(min) 2-3: A-80-32\% e B-20-68\%; Tempo(min) 3-8: A-32\% e B-68\%; Tempo(min) 8-8,1: A-32-80\% e B-68-20\%; Tempo(min) 8,1-20: A-80\% e B$20 \%$; O padrão diluído em água ultrapurificada com concentração final $100 \mu \mathrm{g} / \mathrm{mL}$. O preparo da amostra foi realizado através da reconstituição de 4,0g de didanosina em 200 $\mathrm{mL}$ de água ultrapurificada e $200 \mathrm{~mL}$ de Mylanta Plus ${ }^{\circledR}$, homogeneizando, diluído de modo a obter a concentração final de $100 \mu \mathrm{g} / \mathrm{mL}$. 


\section{RESULTADOS E DISCUSSÃO}

Tabela 1: Resultado dos parâmetros da validação

\begin{tabular}{|c|c|}
\hline Parâmetros & Resultados \\
\hline Faixa Limearidade & $50-150 \mathrm{HgmL}$ \\
\hline Equação da reta & $y=20097 x+31627$ \\
\hline $\mathrm{R}$ & @,9999 \\
\hline \multirow[t]{2}{*}{ Repetibilidade $\%$ ) } & $104,7 \pm 1,1$ \\
\hline & $105,4=0,5\left(\mathrm{~L}_{\mathrm{ab}}-1\right)$ \\
\hline Reprodutubilidade(\%) & $108,3 \pm 1,3,\left(L_{-a b}-2\right)$ \\
\hline Robustez $(\%)$ (coluna) & $105,5 \pm 0,7(\mathrm{C} 1) 104,3 \pm 1,2(\mathrm{C} 2)$ \\
\hline Robustez $(\%)\left({ }^{\circ} \mathrm{C}\right)$ & $105,30 \pm 1,5(\mathrm{~T} 1) 104,3 \pm 1,2(\mathrm{~T} 2) 104,9 \pm 1,3(\mathrm{~T} 3)$ \\
\hline Robustez(\%) (fluxo) & $106,8 \pm 1,9(\mathrm{f} 1) 104,3 \pm 1,2(\mathrm{f} 2) 104,3 \pm 1,5(\mathrm{f} 3)$ \\
\hline $\mathrm{LD}(\mu \mathrm{g} \mathrm{mL})$ & 0,91 ㅆ $\mathrm{gmL}$ \\
\hline $\mathrm{LQ}(\mu \mathrm{g} \mathrm{mL})$ & 3,1 ㅆ $\mathrm{g} \mathrm{mL}$ \\
\hline Exatidão $50 \%$ & $103,1_{\sim} \pm 0,8$ \\
\hline Exatidão $100 \%$ & $102,3, \pm 1,0$ \\
\hline Exatidão $150 \%$ & $103,6 \pm 0,3$ \\
\hline
\end{tabular}
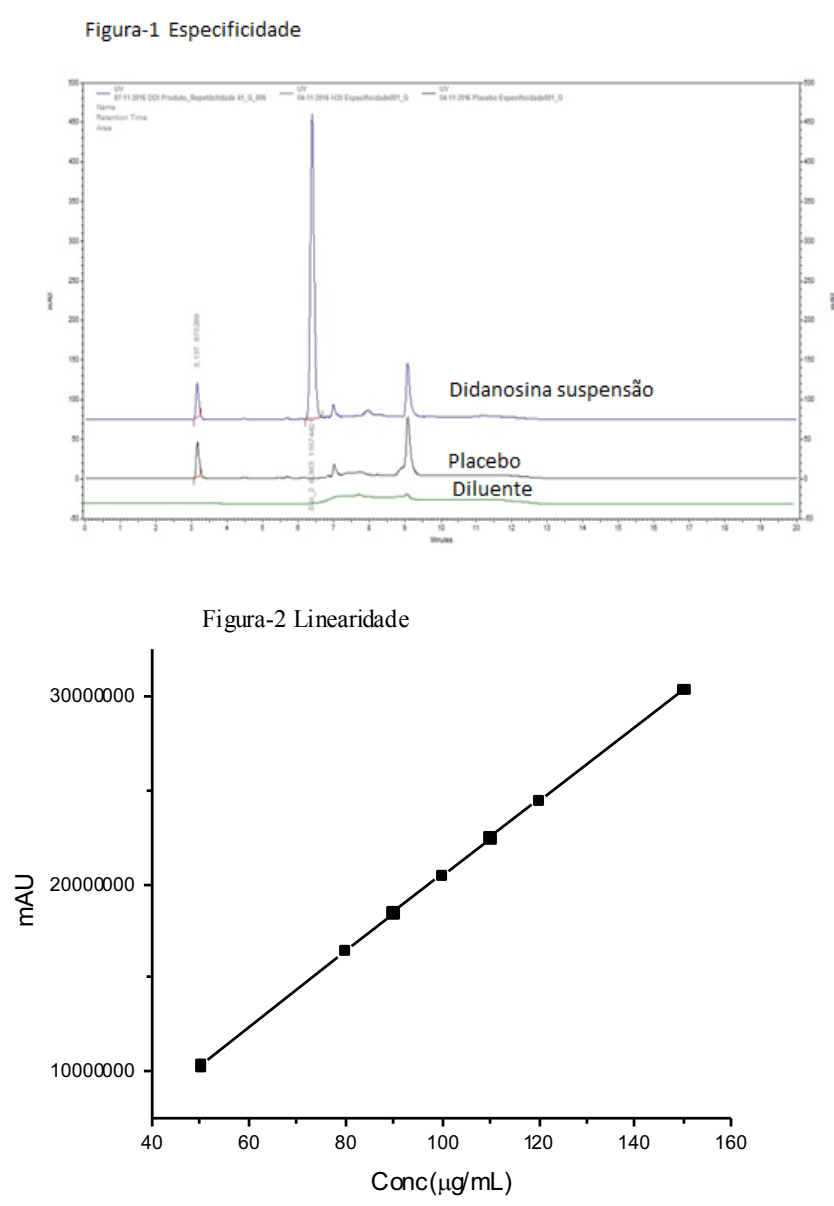

A especificidade foi comprovada através da comparação com a injeção do diluente, placebo e didanosina, onde não foi observada a sobreposição de picos, bem como a interferência do diluente e/ou placebo no tempo de retenção da didanosina, conforme figura 1. A linearidade conforme figura 2, apresentou uma relação linear entre a concentração da amostra e a resposta obtida pelo método. Os parâmetros avaliados no estudo e seus respectivos resultados encontram-se descritos na tabela 1.

O método foi preciso, pois apresentou uma boa repetibilidade e reprodutibilidade com coeficiente de variação abaixo do exigido de $5 \%$ de coeficiente de variação. $O$ método foi robusto para os parâmetros avaliados: coluna cromatográfica, fluxo (avaliado com 0,$97 ; 1,1$ e $3 \mathrm{~mL})$ e temperatura do forno $\left(24 ; 25\right.$ e $\left.26^{\circ} \mathrm{C}\right)$. Obtivemos uma boa recuperação na exatidão nas concentrações baixa, média e alta (tabela 1), inferior a 5\% de coeficiente de variação. Sendo assim, o método foi considerado seletivo para doseamento da didanosina na suspensão oral reconstituída com Mylanta Plus ${ }^{\circledR}$, por CLAE. Todos os resultados foram tratados estatisticamente (ANOVA, teste de t Student) encontram dentro das especificações exigidas.

\section{CONCLUSÃO}

O método analítico de doseamento da didanosina suspensão oral, reconstituída com Mylanta plus ${ }^{\circledR}$, para os parâmetros requeridos para o teste da Categoria I, foi validado segunda a norma aplicada. Desta forma, podemos concluir que o método pode ser 
utilizado na rotina laboratorial do LAFEPE, pois o mesmo atendeu as exigências analíticas.

\section{REFERÊNCIAS}

BRASIL. Ministério da Saúde. Agência Nacional de Vigilância Sanitária. Resolução (RE) no 899, de 29 de maio de 2003. Guia para Validação de Métodos Analíticos e Bioanalíticos, 2003;

BRASIL. Ministério da Saúde. Agência Nacional de Vigilância Sanitária. RDC No 17, de 17 de Abril de 2010, Dispõe sobre as Boas Práticas de Fabricação de Medicamentos; Brasil. Ministério da Saúde.

Fundação Oswaldo Cruz. Memento terapêutico / Ministério da Saúde, Fundação Oswaldo Cruz. - Brasília: Ministério da Saúde, 2006.302 p. - (Série B. Textos Básicos de Saúde);

ANDRÉO FILHO, N; GIORGETTI, L; FERRAZ, H.G. Desenvolvimento de formulações de comprimidos tamponados mastigáveis de didanosina com perfil de dissolução e capacidade neutralizante ácida otimizados, Rev. Ciênc. Farm. Básica Apl.., 30(2) 167-172, 2009.

\section{AGRADECIMENTOS}

Ao Laboratório Farmacêutico de Estado de Pernambuco Governador Miguel Arraes LAFEPE. 